\title{
Implemention Of Social Policies In South Africa: Stances, Progress And Challenges In 20 Years Of Democracy
}

\author{
Thanyani S Madzivhandila \\ Department of Development Planning \& Management, University of Limpopo, South Africa, \\ Private Bag X1106, Sovenga, 0727 \\ thanyani.madzivhandila@ul.ac.za
}

\section{Doi:10.5901/mjss.2014.v5n20p766}

\section{Abstract}

The attainment of democracy in South Africa in 1994 kick started a long journey that was required to transform the poor socioeconomic conditions and the social ills that dominated the large space of the lives particularly of those in rural areas. During the apartheid era, racial exclusion and separate development policies which favour the white minority left the majority of people particularly in rural areas suffering from poverty, unemployment and lack of basic needs. However, the democratic established Constitution (Act 108 of 1996) emphasises the need to strengthen the rights of people to have access to health, sufficient food, water and social security. In that sense, South African government formulated a myriad of legislative and policy measures which were aimed at redressing the moral decay and social ills of the past and to achieve the progressive realization of the these rights. It was on the bases of this moral imperative given the shadow of apartheid and its resulting structural barriers to social and economic development that the promotion of social inclusion, redress and equity became the centre stage of policy formulation. The important question that the paper seeks to ask is why is it that after 20 years of democracy in South Africa, the majority of people are still suffering from poverty, unemployment and lack of basic needs. The purpose of this paper is to discuss the importance of strategic implementation socio-economic policies in South Africa. The paper will be structured as follows; the first part will look at the rural conditions in South Africa assessing transformation progress and challenges; the second part is the analysis of different socio-economic policies in South Africa looking at stances taken towards implementation; thirdly the paper will focus on strides and struggles faced when adopting sustainable socio-economic policies and lastly the paper propose a sustainable way forward towards successful implementation of policies for progressive transformation of the majority of South African citizens.

\section{Introduction}

The notion that even after 20 years in democracy the government of South Africa still cry foul of the inheritance of the country's gross racial inequality, high unemployment and extreme poverty on apartheid creates a conundrum amongst different scholars, political commentator and ordinary people. Different policies aimed at redistributing and transforming the socio-economic conditions patterns that prevailed during apartheid error particularly in rural are areas have not done much to be desired during implementation (Mangaliso \& Mangaliso, 2013; Akech, 2014). Some of the first major policies to be adopted include Reconstruction and Development Programme (RDP) in 1994 and Growth, Employment and Redistribution (GEAR) in 1996. The former aimed at addressing the many social and economic problems facing the country such as housing, shortage of jobs, inadequate education and health care and overall failure of the economy and the latter looked at measures to stabilise and build on the economy which was straggling during this transition period. These policies and other which were formulated after played a big role in the development direction of the country; however, their implementation impacts are found to be wanting (Rizov, 2005; Hall, 2007; Cloete, \& de Coning, 2011; Gumede, 2012; Mangaliso \& Mangaliso, 2013; Akech, 2014). The levels of inequalities are getting higher and higher and the majority of people are still trapped into absolute poverty.

The aim of this paper is to provide a thorough discussing on the challenges of policy implementation in South Africa and coming up with measures relevant in turning policies in to practice. The paper commences by providing a discussing on the socio-economic conditions of rural South Africa. Secondly, the paper provides a discussion on the importance of social policies in the process of transforming the socio-economic conditions in rural areas. Thirdly, the paper provides a discussion on the challenge faced when implementing social policies. Lastly, the paper provides measures to be considered in order to facilitate successful policy implementation and a conclusion. 


\section{Rural South Africa: Socio-Economic Progress and Challenges}

The legacy of apartheid which prompted deep entrenched socio-economic inequality based on racial outlines has left a far reaching impact that is still haunt South Africa today (Cloete, \& de Coning, 2011; Gumede, 2012). However, the country is still regarded as the most developed and modern compared to other Africa countries in terms of available natural resources, developed agricultural sector and significant manufacturing capacity. South African government since 1994 has embarked of a journey been to stimulate basic policies aimed at reconstruction and development of the society. These policy prescripts were intended to provide for basic needs to all, growing the economy and promoting social development (Littig, \& Griebler, 2005; Moller, 2006; Gumede, 2012). Ironically, even after 20 years of democracy the majority of the country's inhabitants particularly those living in rural areas are still affected by extreme poverty. The average incomes are lower in rural areas than the towns and cities and the proportions of people living below specified poverty lines are higher (Desai, \& Potter 2002).

Rural areas in South Africa are still recognised and associated with spaces where human settlement only occupy a small patches of the land scape, with poor infrastructure development, concentration of illiterate/unskilled people, unequal distribution of assets, skewed distribution of income, employment opportunities and access to social services. In other words the post-apartheid South Africa socio-economic status particularly in rural areas still reflects the underdevelopment that can be attributed to problems with stability, growth and distribution; segregated planning approach and scattered residential and farming settlements without viable economic and social linkages to the more economically active areas of the country; underutilisation and/or unsustainable use of natural resources, poor or lack of access to socio-economic infrastructure and service, lack of access to water or lack of water sources for both household and agricultural development; low literacy, skills levels and migratory labour practice; and overdependence on social grants and other forms of social security (Gumede, 2012; Akech, 2014;). The convolution of these rural features has created a far reaching impact on the implementation of social policies aimed at improving the standard of living of the poor, creating employment opportunities and capacity building among the unskilled able bodies in the rural areas (Murdoch, 2000; Rizov, 2005; Republic of South Africa (RSA) 2011; Mangaliso \& Mangaliso, 2013). Moreover, the concentration of poverty in rural areas has been a stumbling block for development to take place smoothly and sustainably in these areas.

\section{Socio-Economic Policies in South Africa: Stances Towards Transformation}

Major policy prescription including the RDP of 1994 and GEAR of 1996, the 2005 Accelerated and Shared Growth Initiative for South Africa (AsgiSA) and the 2012 National Development Plan (NDP) has been formulated to shape the development direction of the country. RDP was a first major policy aimed at to accelerating social transformation needed for post-apartheid South Africa (Rizov, 2005; Hall, 2007; Gumede, 2012). This policy focused on addressing the many social and economic problems facing the country such as addressing housing, shortage of jobs, inadequate education and health care and overall failure of the economy. It proposed job creation through public works, the building of houses and the provision of services that would be done in a way that will create employment. GEAR which was a macroeconomic framework in its nature was intended to stabilise and rescue the economy that was in recession at the time and already falling apart. AsgiSA intention was to accelerate the growth of the economy as well as wealth redistribution. It was sought to bring the desperately needed hope for social change through integrated social and economic development (Gumede, 2012). The NDP or the Vision 2030 as it is also known is aimed at bringing consensus building mechanism towards a maximum reduction of poverty, inequality and unemployment. The adoption of all these policies has been to facilitate paramount social transformation through integrated social and economic development by government in collaboration with social partners, and seeking appropriate ways to unpack and address the deep-rooted structural causes of poverty and inequality in the country.

In order for policies to bring adequate transformation to the society, there are a number of basic and important strands. Social policies should promote social welfare where education, health, nutrition, social security (pension) are taken into consideration to enhance human capital encompasses, access to adequate and secure livelihoods and income and to boost macro-economic growth i.e. meeting basic needs and poverty alleviation (Murdoch, 2000; Mkandawire, 2001). Secondly, social policies should stimulate social protection in terms of construction of social safety nets to tackle absolute poverty. Issues such as social funds, condition cash transfer measures, social investment, environmental and social safeguard can be emphasized to protect and prevent harmful impacts to the weak and vulnerable. Social protection includes labour market intervention, natural disaster management, vulnerability assessment and monitoring. Lastly, social policies should act as a driving force behind social development including community driven development, social accountability, conflict prevention, participation and civil engagement amongst others (Mkandawire, 2001). 
In South Africa social development has focus on promoting and enhancing livelihoods activities of the poor in rural areas. The success to these interventions is dependent on the involvement of target groups through integrated participatory systems, where by policy makers plan with the people rather than for the people in meeting their felt needs. Such participation will give the target groups a sense of belonging as well as get them committed to the successful implementation of the policy (Mkandawire, 2001; Gumede, 2012). However, social policy reflects a broader if not more fragmented view of social development. It is conceived as involving overall and prior concern with social development, and as a key instrument that works in tandem with economic policy to ensure equitable and socially sustainable development. In other words social policy implementation will only be successful if it works hand in hand with economic policy towards advancing both subjective and objective wellbeing of the society. Collective interventions directly affecting transformation in social welfare, social institutions and social relations are critical. In other words, social policy should transform social welfare, social institution and social relations.

The government has a huge role to play in the facilitation of the implementation of social policies for transformation and social development. Government institutions should adopt social policies which will become common currency to support strategies that are pertinent to the empowerment of the society and other stakeholder that are deemed relevant in the process of transformation (Rizov, 2005; Hall, 2007; Mangaliso \& Mangaliso, 2013; Akech, 2014). For any government to be judged as administrative competent there must be evidence of bridging the gap between the intention of the policy and the actual achievement of the policy. The government role should be beyond formulating policy as a residual category 'safety nets' that merely counteract policy failure or development disaster. Moreover, policies should not be introduced as a way to correct the pathologies of economic development. Rather, policies should be formulated with a purpose of redistributing income in order to move towards equity, increase social cohesion and promotion and accumulation of social capital and stability which in return is essential for growing local economies and livelihoods (Hall, 2007). To successfully transform society, social policies should seek for the adoption of measures that will bring about developmental state, where the society is able to self-sustain its livelihood and development efforts amid different challenges faced.

\section{Struggles in the Quest Towards Adopting Sustainable Socio-Economic Policies}

Even if a great measure of conceptual and operational integration and collaboration were possible in theory among the diverse arm of social policy, there remains a major practical obstacle to its mainstreaming in to the society. In the past few decades, policies have been rolled out regularly in developing nations but, most of the time, without achieving the desired results. It has been observed that policy implementation is one of the major problems confronting these nations (Cloete, \& de Coning, 2011; Booysen, 2013). For example, South African developmental challenge has not only been about faster growth, but also broadening participation and accelerating the pace of social advancement through policy implementation to overcome poverty and inequality. What has been difficult for the country is not the government commitment to formulate policy that will solve the complex problems faced, but the ability to implement policy and social development intervention at grassroots level were deep-seated poverty and inequality reign. South Africa is approaching the end of its second decade after democracy but poverty continues to be widespread, unemployment remains high and many people lack necessities. The country is also recorded to have some of the world class policies and positive economy growth; however, that has not automatically erase inequality among citizens.

Lack of communication, resources, dispositions or attitude and bureaucratic structures are some of the implementation problems which derail the efforts to implement sustainable socio-economic policies. Some of the factors to influence this derail include corruption, lack of continuity in government policies, inadequate human and material resources, all of which often lead to implementation gap i.e. the widening of the distance between stated policy goal and the realisation of such planned goals (Mkandawire, 2001; Cloete, \& de Coning, 2011). However, when dealing with complex policies the fact that communication, resources and positive disposition are put in place does not guarantee implementation success if there is no efficient bureaucratic structure. Understanding of implementation is the belief that it is not simply a managerial or administrative problem, it is a political process concerned with who gets what, when, how, and from whom. Hence, this strand has resulted into other serious problems such as bribery, nepotism, maladministration and corruption within the political cadre's cycle, leading greatly to the failure of policy implementation in developing countries (Mkandawire, 2001; Booysen, 2013). Also, implementation gap may arise from the policy itself when such a policy emanates from government rather than from the target groups (top-down approach). If target groups are involved, they are able to give the correct account to social, political, economic and administrative conditions of the local area and that contribute to prioritisation of adequate implementation of policies. Lack of proper integrated channels for stakeholder engagement and organisational fragmentation has also resulted in to failure of policy implementation (Littig, \& Griebler, 
2005; Moller, 2006; Cloete, \& de Coning, 2011; Booysen, 2013). This disparity has hindered implementation of policies and resulted in wastage of scarce resources, inhibit change, create confusion, lead to policies working at cross-purposes and results in important functions being overlooked. The complex interactions of the outlined activities which are deterring the successful implementation of social policies need to be strategically addressed in order to turn policy in to practice.

\section{Proposed Sustainable Way Forward}

The success to policy implementation is not a straight forward process that is based on a single phenomenon but a variety of complex variable that should be taken to consideration. So in order to have a successful implementation of policies going forward, the process should be based on the conversion of physical and financial resources into concrete service-delivery outputs in the form of facilities and services, or into other concrete outputs aimed at achieving policy objective (Murdoch, 2000; Mkandawire, 2001; Rizov, 2005). Such a process should subsequent forge the links in the causal chain of activities in order to obtain the desired results. The following are some of the factors that should be taken into consideration in order to successfully implement social policies: Targeted beneficiaries and other stakeholders should be involved from the formulation stage of the policy until its implementation. However, training should be provided in order to strengthen the ability of the stakeholder participation. Stakeholder engagement also helps to strengthen positive disposition or attitude in policy implementation. The level of success will depend to a large extent on how the implementers together with the beneficiaries see the policies as affecting their organisational and personal interests. Where a policy will results in reduction of pay, low self-esteem, or loss of position to the implementers, the attitude will be affected adversely; Effective communication allows for orders to implement policies to be transmitted to the appropriate personnel in a clear manner while such orders are accurate and consistent. That is, implementation instructions that are not clearly transmitted, or distorted in transmission, that are vague, or that are inconsistent may cause serious obstacles to policy implementation. Also, inadequate information can lead to a misunderstanding on the part of the implementers who may be confused on what exactly are required of them; and Man power and financial resources also play a major role on the success of policy implementation. Where implementation orders are clear, consistent and accurate transmitted, the absence of adequate resources will results in implementation problems (Mkandawire, 2001).

All these factors and others should be consider if social policies are to be implemented successfully. Thus, guaranteeing that the impact of the policy is sustainable. In the modern society, social policy should move away from seeing social protection as simply a short-term welfare measure and towards a long-term security perspective involving livelihoods strengthening and the adoption of a rights-based approach (Mkandawire, 2001; Rizov, 2005). The process should be in a way that it converts financial, material, technical and human inputs into outputs goods and services where the society are being transformed to be self-sustaining and dependable.

\section{Conclusion}

The is a serious need for self-introspection of government in South Africa after 20 year of democracy in order that new stances can be taken towards resolving socio-economic struggles that the majority of people still face particularly in rural areas. Strategic planning, coordination and implementation should be the final acid test for a policy to be successful. Such a process should consider different factors that are pertinent to the sustainability of policy implementation. Factors such stakeholder engagement, effective communication, adequate human and financial resources and also formulation of monitoring and evaluation measures are paramount to the realisation of a successful policy implementation. Amid different challenges such as the high rate of corruption, limited skills and finance, successful policy implementation should play a major role in the transformation of socio-economic conditions of South African society. The government together with different stakeholders should be able to build capacity in order that they can effectively implement policies that will eliminate poverty, unemployment and inequality and political intolerance in order to fast-track progress towards a better life for all.

\section{References}

Akech, M. 2014. Globalization, the rule of administrative law, and the realization of democratic governance in Africa: realities, challenges, and prospects. Indiana Journal of Global Legal Studies, 20(1):339-375.

Booysen, S. 2013. Twenty Years of South African Democracy: Citizen Views of Human Rights, Governance and the Political System. Johannesburg: Freedom House.

Cloete, F. \& de Coning, C. (Eds) 2011. Improving Public Policy: Theory, Practice and Results. Pretoria: Van Schaik Publishers. 
Desai, V. \& Potter, R.B. (eds.) 2002. The Companion to Development Studies. London: Hodder Arnold.

Gumede, V. (2012). Social and Economic Transformation in Post-Apartheid South Africa-Policies, Progress and Proposals. Pretoria: University of South Africa.

Hall, A. 2007. Social policies at the World Bank: paradigms and challenges. Global Social Policy, 7(2):151-175.

Littig, B. \& Griebler, E. 2005. Social sustainability: a catchword between political pragmatism and social theory. International Journal Sustainable Development, 8(1/2):65-79.

Makinde, T. 2005. Problems of policy implementation in developing nations: the Nigerian experience. Journal of Social Science, 11(1):63-69.

Mangaliso, M.P. \& Mangaliso, N.A. 2013. Transformation to an equitable socioeconomic dispensation: observations and reflections on South Africa. Journal of Black Studies, 44(5)529-546.

Mkandawire, T. 2001. Social Policy in a Development Context. Geneva: United Nations Research Institute for Social Development.

Moller, V. 2006. Quality of life in South Africa: the first ten years of democracy. Social Indicators Research, 81:181-201

Murdoch, J. 2000. Networks-a new paradigm of rural development? Journal of Rural Studies, 16:407-419.

Republic of South Africa (RSA) 1996. Constitution. Pretoria: Government Printers

Republic of South Africa (RSA) 2011. Rural Development and Land Reform General Amendment Act. Pretoria: Government Printers.

Rizov, M. 2005. Rural development under the European CAP: the role of diversity. Social Science Journal, 42:621-628. 